\title{
Stability of additivity and fixed point methods
}

\section{Janusz Brzdęk*}

"Correspondence:

jbrzdek@up.krakow.pl

Department of Mathematics,

Pedagogical University,

Podchorążych 2, Kraków, 30-084,

Poland

\begin{abstract}
We show that the fixed point methods allow to investigate Ulam's type stability of additivity quite efficiently and precisely. Using them we generalize, extend and complement some earlier classical results concerning the stability of the additive Cauchy equation.
\end{abstract}

MSC: 39B82; 47H10

Keywords: additivity; fixed point; Ulam stability

\section{Introduction}

In applications quite often we have to do with functions that satisfy some equations only approximately. One of possible ways to deal with them is just to replace such functions by corresponding (in suitable ways) exact solutions to those equations. But there of course arises the issue of errors which we commit in this way. Some tools to evaluate such errors are provided within the theory of Ulam's type stability. For instance, we can introduce the following definition, which somehow describes the main ideas of such stability notion for the Cauchy equation

$$
f(x+y)=f(x)+f(y)
$$

Definition 1 Let $(A,+)$ and $(X,+)$ be semigroups, $d$ be a metric in $X, \mathcal{E} \subset \mathcal{C} \subset \mathbb{R}_{+}^{A^{2}}$ be nonempty, and $\mathcal{T}$ be an operator mapping $\mathcal{C}$ into $\mathbb{R}_{+}^{A}\left(\mathbb{R}_{+}\right.$stands for the set of nonnegative reals). We say that Cauchy equation $(1)$ is $(\mathcal{E}, \mathcal{T})$-stable provided for every $\varepsilon \in \mathcal{E}$ and $\varphi_{0} \in$ $X^{A}$ with

$$
d\left(\varphi_{0}(x+y), \varphi_{0}(x)+\varphi_{0}(y)\right) \leq \varepsilon(x, y), \quad x, y \in A,
$$

there exists a solution $\varphi \in X^{A}$ of equation (1) such that

$$
d\left(\varphi(x), \varphi_{0}(x)\right) \leq \mathcal{T} \varepsilon(x), \quad x \in A
$$

(As usual, $C^{D}$ denotes the family of all functions mapping a set $D \neq \emptyset$ into a set $C \neq \emptyset$.) Roughly speaking, $(\mathcal{E}, \mathcal{T})$-stability of equation (1) means that every approximate (in the sense of (2)) solution of (1) is always close (in the sense of (3)) to an exact solution to (1).

Let us mention that this type of stability has been a very popular subject of investigations for the last nearly fifty years (see, e.g., [1-10]). The main motivation for it was given by S.M. Ulam $(c f .[4,11])$ in 1940 in his talk at the University of Wisconsin, where he presented, in particular, the following problem.

C2013 Brzdęk; licensee Springer. This is an Open Access article distributed under the terms of the Creative Commons Attribution License (http://creativecommons.org/licenses/by/2.0), which permits unrestricted use, distribution, and reproduction in any medium, provided the original work is properly cited. 
Let $G_{1}$ be a group and $\left(G_{2}, d\right)$ be a metric group. Given $\varepsilon>0$, does there exist $\delta>0$ such that iff : $G_{1} \rightarrow G_{2}$ satisfies

$$
d(f(x y), f(x) f(y))<\delta, \quad x, y \in G_{1},
$$

then a homomorphism $T: G_{1} \rightarrow G_{2}$ exists with $d(f(x), T(x))<\varepsilon$ for $x \in G_{1}$ ?

Hyers [4] published a partial answer to it, which can be stated as follows.

Let $E$ and $Y$ be Banach spaces and $\varepsilon>0$. Then, for every $g: E \rightarrow Y$ with

$$
\sup _{x, y \in E}\|g(x+y)-g(x)-g(y)\| \leq \varepsilon
$$

there is a unique $f: E \rightarrow Y$ that is additive (i.e., satisfies equation (1)) and such that

$$
\sup _{x \in E}\|g(x)-f(x)\| \leq \varepsilon
$$

Quite often we describe that result of Hyers simply saying that Cauchy functional equation (1) is Hyers-Ulam stable (or has the Hyers-Ulam stability).

In the next few years, Hyers and Ulam published some further stability results for polynomial functions, isometries and convex functions in [12-15]. Let us mention yet that now we are aware of an earlier (than that of Hyers) result concerning such stability that is due to Pólya and Szegö [16, Teil I, Aufgabe 99] (see also [17, Part I, Ch. 3, Problem 99]) and reads as follows ( $\mathbb{N}$ stands for the set of positive integers).

For every real sequence $\left(a_{n}\right)_{n \in \mathbb{N}}$ with $\sup _{n, m \in \mathbb{N}}\left|a_{n+m}-a_{n}-a_{m}\right| \leq 1$, there is a real number $\omega$ such that $\sup _{n \in \mathbb{N}}\left|a_{n}-\omega n\right| \leq 1$. Moreover, $\omega=\lim _{n \rightarrow \infty} a_{n} / n$.

The next theorem is considered to be one of the most classical results.

Theorem 1 Let $E_{1}$ and $E_{2}$ be two normed spaces, $E_{2}$ be complete, $c \geq 0$ and $p \neq 1$ be fixed real numbers. Let $f: E_{1} \rightarrow E_{2}$ be a mapping such that

$$
\|f(x+y)-f(x)-f(y)\| \leq c\left(\|x\|^{p}+\|y\|^{p}\right), \quad x, y \in E_{1} \backslash\{0\} .
$$

Then there exists a unique additive function $T: E_{1} \rightarrow E_{2}$ with

$$
\|f(x)-T(x)\| \leq \frac{c\|x\|^{p}}{\left|2^{p-1}-1\right|}, \quad x \in E_{1} \backslash\{0\}
$$

It was motivated by Th.M. Rassias (see [18-20]) and is composed of the outcomes in [18, $21,22]$. Note that Theorem 1 with $p=0$ yields the result of Hyers and it is known (see [22]; $c f$. also $[23,24])$ that for $p=1$ an analogous result is not valid. Moreover, it was shown in [25] that estimation (5) is optimum for $p \geq 0$ in the general case.

Theorem 1 has a very nice simple form. However, recently, it was shown in [26] that it can be significantly improved; namely, in the case $p<0$, each $f: E_{1} \rightarrow E_{2}$ satisfying (4) must actually be additive and the assumption of completeness of $E_{2}$ is not necessary in such a situation. So, taking into account that result in [26], we can reformulate Theorem 1 in the following way. 
Theorem 2 Let $E_{1}$ and $E_{2}$ be two normed spaces and $c \geq 0$ and $p \neq 1$ be fixed real numbers. Let $f: E_{1} \rightarrow E_{2}$ be a mapping satisfying (4). If $p \geq 0$ and $E_{2}$ is complete, then there exists a unique additive function $T: E_{1} \rightarrow E_{2}$ such that (5) holds. If $p<0$, then $f$ is additive.

The second statement of Theorem 2, for $p<0$, can be described as the $\varphi$-hyperstability of the additive Cauchy equation for $\varphi(x, y) \equiv c\left(\|x\|^{p}+\|y\|^{p}\right)$. Unfortunately, such result does not remain valid if we restrict the domain of $f$, as the following remark shows it.

Remark 1 Let $p<0, a \geq 0, I=(a, \infty)$, and $f, T: I \rightarrow \mathbb{R}$ be given by $T(x)=0$ and $f(x)=x^{p}$ for $x \in I$. Then, clearly,

$$
|f(x)-T(x)|=x^{p}, \quad x \in I,
$$

and (cf. Example 1)

$$
|f(x+y)-f(x)-f(y)| \leq x^{p}+y^{p}, \quad x, y \in I .
$$

\section{The main result}

In this paper we prove the following complement to Theorem 1, which covers also the situation described in Remark 1 (see Remark 2).

Theorem 3 Let $(X,+)$ be a commutative semigroup, $(E,+)$ be a commutative group, $d$ be a complete metric in $E$ which is invariant (i.e., $d(x+z, y+z)=d(x, y)$ for $x, y, z \in X)$, and $h: X \rightarrow \mathbb{R}_{+}$be a function such that

$$
M_{0}:=\{n \in \mathbb{N}: s(n)+s(n+1)<1\} \neq \emptyset,
$$

where $s(n):=\inf \left\{t \in \mathbb{R}_{+}: h(n x) \leq\right.$ th $(x)$ for all $\left.x \in X\right\}$ for $n \in \mathbb{N}$. Assume that $f: X \rightarrow E$ satisfies the inequality

$$
d(f(x+y), f(x)+f(y)) \leq h(x)+h(y), \quad x, y \in X .
$$

Then there exists a unique additive $T: X \rightarrow E$ such that

$$
d(f(x), T(x)) \leq s_{0} h(x), \quad x \in X,
$$

with

$$
s_{0}:=\inf \left\{\frac{1+s(n)}{1-s(n)-s(n+1)}: n \in M_{0}\right\} .
$$

It is easily seen that Theorem 3 yields the subsequent corollary.

Corollary 1 Let $X, E$ and $d$ be as in Theorem 3 and $h: X \rightarrow(0, \infty)$ be such that

$$
\liminf _{n \rightarrow \infty} \sup _{x \in X} \frac{h(n x)+h((1+n) x)}{h(x)}=0 .
$$


Assume that $f: X \rightarrow E$ satisfies (6). Then there is a unique additive $T: X \rightarrow E$ with

$$
d(f(x), T(x)) \leq h(x), \quad x \in X
$$

Remark 2 If $E_{1}$ and $E_{2}$ are normed spaces and $X$ is a subsemigroup of the group $\left(E_{1},+\right)$ such that $0 \notin X$, then it is easily seen that the function $h: X \rightarrow E_{2}$, given by $h(x)=c\|x\|^{p}$ for $x \in X$, with some real $p<0$ and $c>0$, fulfils condition (8). This shows that Corollary 1 (and therefore Theorem 3, as well) complements Theorem 2 and in particular also Theorem 1. Note that for such $h$, (9) takes the form

$$
\|f(x)-T(x)\| \leq c\|x\|^{p}, \quad x \in X
$$

which is sharper than (5) for $p<0$.

A bit more involved example of $h: X \rightarrow E_{2}$ satisfying (8) we obtain taking

$$
h(x)=\gamma(x) A(x)^{p}, \quad x \in X
$$

for any real $p<0$, any bounded function $\gamma: X \rightarrow \mathbb{R}$ with $\inf \gamma(X)>0$, and any $A: X \rightarrow$ $(0, \infty)$ such that $A(n x) \geq n A(x)$ for $x \in X, \in \mathbb{N}$ (for instance, we can take $A(x):=\|\alpha(x)\|$ for $x \in X$, with some additive $\left.\alpha: E_{1} \rightarrow E_{2}\right)$.

In some cases, estimation (9) provided in Corollary 1 is optimum as the subsequent example shows. Unfortunately, this is not always the case, because the possibly sharpest such estimation we have in Theorem 2 for $p<0$.

Example 1 Let $p<0, a \geq 0, I=[a, \infty)$, and $A: I \rightarrow \mathbb{R}$ be additive and such that $X:=\{x \in I$ : $A(x)>0\} \neq \emptyset$. Write $h(x)=A(x)^{p}$ for $x \in X$. Then it is easily seen that $X$ is a subsemigroup of the semigroup $(I,+)$ and (8) is valid. Define $f, T: X \rightarrow \mathbb{R}$ by $T(x)=0$ and $f(x)=A(x)^{p}$ for $x \in X$. Then

$$
|f(x)-T(x)|=A(x)^{p}=h(x), \quad x \in X
$$

We show that

$$
|f(x+y)-f(x)-f(y)| \leq h(x)+h(y), \quad x, y \in X .
$$

Actually, the calculations are very elementary, but for the convenience of readers, we provide them.

So, fix $x, y \in X$. Suppose, for instance, that $A(x) \leq A(y)$. Then

$$
A(x)+A(y) \geq 2 A(x)
$$

which means that

$$
A(x+y)^{p}=(A(x)+A(y))^{p} \leq 2^{p} A(x)^{p}<A(x)^{p}<A(x)^{p}+A(y)^{p}
$$


and consequently

$$
\begin{aligned}
|f(x+y)-f(x)-f(y)| & =A(x)^{p}+A(y)^{p}-A(x+y)^{p} \\
& \leq A(x)^{p}+A(y)^{p}=h(x)+h(y) .
\end{aligned}
$$

\section{Auxiliary result}

The proof of Theorem 3 is based on a fixed point result that can be easily derived from [27, Theorem 2] (cf. [28, Theorem 1] and [29]). Let us mention that [27, Theorem 2] was already used, in a similar way as here, for the first time in [30] for proving some stability results for the functional equation of $\mathrm{p}$-Wright affine functions, next in [26, 31] in proving hyperstability of the Cauchy equation, and (very recently) also for investigations of stability and hyperstability of some other equations in [32-34] (the Jensen equation, the general linear equation, and the Drygas functional equation, respectively).

The fixed point approach to Ulam's type stability was proposed for the first time in [35] ( $c f$. [36] for a generalization; see also [37]) and later applied in numerous papers; for a survey on this subject, we refer to [38].

We need to introduce the following hypotheses.

(H1) $X$ is a nonempty set and $(Y, d)$ is a complete metric space.

(H2) $f_{1}, f_{2}: X \rightarrow X$ are given maps.

(H3) $\mathcal{T}: Y^{X} \rightarrow Y^{X}$ is an operator satisfying the inequality

$$
d(\mathcal{T} \xi(x), \mathcal{T} \mu(x)) \leq d\left(\xi\left(f_{1}(x)\right), \mu\left(f_{1}(x)\right)\right)+d\left(\xi\left(f_{2}(x)\right), \mu\left(f_{2}(x)\right)\right), \quad \xi, \mu \in Y^{X}, x \in X .
$$

(H4) $\Lambda: \mathbb{R}_{+}^{X} \rightarrow \mathbb{R}_{+}^{X}$ is an operator defined by

$$
\Lambda \delta(x):=\delta\left(f_{1}(x)\right)+\delta\left(f_{2}(x)\right), \quad \delta \in \mathbb{R}_{+}^{X}, x \in X
$$

Now we are in a position to present the above mentioned fixed point result following from [27, Theorem 2].

Theorem 4 Assume that hypotheses (H1)-(H4) are valid. Suppose that there exist functions $\varepsilon: X \rightarrow \mathbb{R}_{+}$and $\varphi: X \rightarrow Y$ such that

$$
\|\mathcal{T} \varphi(x)-\varphi(x)\| \leq \varepsilon(x), \quad \varepsilon^{*}(x):=\sum_{n=0}^{\infty}\left(\Lambda^{n} \varepsilon\right)(x)<\infty, \quad x \in X .
$$

Then there exists a unique fixed point $\psi$ of $\mathcal{T}$ with

$$
\|\varphi(x)-\psi(x)\| \leq \varepsilon^{*}(x), \quad x \in X .
$$

Moreover, $\psi(x):=\lim _{n \rightarrow \infty}\left(\mathcal{T}^{n} \varphi\right)(x)$ for $x \in X$.

\section{Proof of Theorem 3}

Note that (6) with $y=m x$ gives

$$
d(f((1+m) x), f(x)+f(m x)) \leq(1+s(m)) h(x), \quad x \in X, m \in \mathbb{N} .
$$


Define operators $\mathcal{T}_{m}: E^{X} \rightarrow E^{X}$ and $\Lambda_{m}: \mathbb{R}_{+}^{X} \rightarrow \mathbb{R}_{+}^{X}$ by

$$
\begin{array}{ll}
\mathcal{T}_{m} \xi(x):=\xi((1+m) x)-\xi(m x), & x \in X, \xi \in E^{X}, m \in \mathbb{N} \\
\Lambda_{m} \delta(x):=\delta((1+m) x)+\delta(m x), & x \in X, \delta \in \mathbb{R}_{+}^{X}, m \in \mathbb{N} .
\end{array}
$$

Then it is easily seen that, for each $m \in \mathbb{N}, \Lambda:=\Lambda_{m}$ has the form described in (H4) with $f_{1}(x)=m x$ and $f_{2}(x)=(1+m) x$. Moreover, since $d$ is invariant, (11) can be written in the form

$$
d\left(\mathcal{T}_{m} f(x), f(x)\right) \leq(1+s(m)) h(x)=: \varepsilon_{m}(x), \quad x \in X, m \in \mathbb{N},
$$

and

$$
\begin{aligned}
& d\left(\mathcal{T}_{m} \xi(x), \mathcal{T}_{m} \mu(x)\right) \\
& \quad=d(\xi((1+m) x)-\xi(m x), \mu((1+m) x)-\mu(m x)) \\
& \quad \leq d(\xi((1+m) x), \mu((1+m) x))+d(\xi(m x), \mu(m x))
\end{aligned}
$$

for every $\xi, \mu \in E^{X}, x \in X, m \in \mathbb{N}$. Consequently, for each $m \in \mathbb{N}$, also (H3) is valid with $Y:=E$ and $\mathcal{T}:=\mathcal{T}_{m}$.

It is easy to show by induction on $n$ that

$$
\Lambda_{m}^{n} \varepsilon_{m}(x) \leq(1+s(m)) h(x)(s(m)+s(1+m))^{n}
$$

for $x \in X, n \in \mathbb{N}_{0}$ (nonnegative integers) and $m \in M_{0}$. Hence

$$
\begin{aligned}
\varepsilon_{m}^{*}(x) & :=\sum_{n=0}^{\infty}\left(\Lambda_{m}^{n} \varepsilon_{m}\right)(x) \\
& \leq(1+s(m)) h(x) \sum_{n=0}^{\infty}(s(m)+s(1+m))^{n} \\
& =\frac{(1+s(m)) h(x)}{1-s(m)-s(1+m)}, \quad x \in X, m \in M_{0} .
\end{aligned}
$$

Now, we can use Theorem 4 with $Y=E$ and $\varphi=f$. According to it, the limit

$$
T_{m}(x):=\lim _{n \rightarrow \infty}\left(\mathcal{T}_{m}^{n} f\right)(x)
$$

exists for each $x \in X$ and $m \in M_{0}$,

$$
d\left(f(x), T_{m}(x)\right) \leq \frac{(1+s(m)) h(x)}{1-s(m)-s(1+m))}, \quad x \in X, m \in M_{0}
$$

and the function $T_{m}: X \rightarrow E$, defined in this way, is a solution of the equation

$$
T(x)=T((1+m) x)-T(m x) .
$$


Now we show that

$$
\begin{aligned}
& d\left(\mathcal{T}_{m}^{n} f(x+y), \mathcal{T}_{m}^{n} f(x)+\mathcal{T}_{m}^{n} f(y)\right) \\
& \quad \leq(s(m)+s(1+m))^{n}(h(x)+h(y))
\end{aligned}
$$

for every $x, y \in X, n \in \mathbb{N}_{0}$ and $m \in M_{0}$. Since the case $n=0$ is just (6), take $k \in \mathbb{N}_{0}$ and assume that (17) holds for $n=k$ and every $x, y \in X, m \in M_{0}$. Then

$$
\begin{aligned}
& d\left(\mathcal{T}_{m}^{k+1} f(x+y), \mathcal{T}_{m}^{k+1} f(x)+\mathcal{T}_{m}^{k+1} f(y)\right) \\
&= d\left(\mathcal{T}_{m}^{k} f((1+m)(x+y))-\mathcal{T}_{m}^{k} f(m(x+y)),\right. \\
&\left.\mathcal{T}_{m}^{k} f((1+m) x)-\mathcal{T}_{m}^{k} f(m x)+\mathcal{T}_{m}^{k} f((1+m) y)-\mathcal{T}_{m}^{k} f(m y)\right) \\
& \leq d\left(\mathcal{T}_{m}^{k} f((1+m) x+(1+m) y), \mathcal{T}_{m}^{k} f((1+m) x)+\mathcal{T}_{m}^{k} f((1+m) y)\right) \\
&+d\left(\mathcal{T}_{m}^{k} f(m x+m y), \mathcal{T}_{m}^{k} f(m x)+\mathcal{T}_{m}^{k} f(m y)\right) \\
& \leq(s(m)+s(1+m))^{k}(h((1+m) x)+h((1+m) y)) \\
&+(s(m)+s(1+m))^{k}(h(m x)+h(m y)) \\
& \leq(s(m)+s(1+m))^{k+1}(h(x)+h(y)), \quad x, y \in X, m \in M_{0} .
\end{aligned}
$$

Thus, by induction we have shown that (17) holds for every $x, y \in X, n \in \mathbb{N}_{0}$, and $m \in M_{0}$. Letting $n \rightarrow \infty$ in (17), we obtain the equality

$$
T_{m}(x+y)=T_{m}(x)+T_{m}(y), \quad x, y \in X, m \in M_{0} .
$$

Next, we prove that each additive function $T: X \rightarrow Y$ satisfying the inequality

$$
d(f(x), T(x)) \leq \operatorname{Lh}(x), \quad x \in X
$$

with some $L>0$, is equal to $T_{m}$ for each $m \in M_{0}$. To this end, fix $m_{0} \in M_{0}$ and an additive $T: X \rightarrow Y$ satisfying (19). Note that by (15),

$$
\begin{aligned}
d\left(T(x), T_{m_{0}}(x)\right) & \leq d(T(x), f(x))+d\left(f(x), T_{m_{0}}(x)\right) \\
& =L_{0} h(x) \sum_{n=0}^{\infty}\left(s\left(m_{0}\right)+s\left(1+m_{0}\right)\right)^{n}, \quad x \in X
\end{aligned}
$$

for some $L_{0}>0$ (the case $h(x) \equiv 0$ is trivial, so we exclude it here). Observe yet that $T$ and $T_{m_{0}}$ are solutions to equation (16) for all $m \in M_{0}$.

We show that for each $j \in \mathbb{N}_{0}$,

$$
d\left(T(x), T_{m_{0}}(x)\right) \leq L_{0} h(x) \sum_{n=j}^{\infty}\left(s\left(m_{0}\right)+s\left(1+m_{0}\right)\right)^{n}, \quad x \in X
$$


The case $j=0$ is exactly (20). So, fix $l \in \mathbb{N}_{0}$ and assume that (21) holds for $j=l$. Then, in view of (20),

$$
\begin{aligned}
& d\left(T(x), T_{m_{0}}(x)\right)=d\left(T\left(\left(1+m_{0}\right) x\right)-T\left(m_{0} x\right), T_{m_{0}}\left(\left(1+m_{0}\right) x\right)-T_{m_{0}}\left(m_{0} x\right)\right) \\
& \quad \leq d\left(T\left(\left(1+m_{0}\right) x\right), T_{m_{0}}\left(\left(1+m_{0}\right) x\right)\right)+d\left(T\left(m_{0} x\right), T_{m_{0}}\left(m_{0} x\right)\right) \\
& \quad \leq L_{0}\left(h\left(\left(1+m_{0}\right) x\right)+h\left(m_{0} x\right)\right) \sum_{n=l}^{\infty}\left(s\left(m_{0}\right)+s\left(1+m_{0}\right)\right)^{n} \\
& \quad \leq L_{0} h(x) \sum_{n=l+1}^{\infty}\left(s\left(m_{0}\right)+s\left(1+m_{0}\right)\right)^{n}, \quad x \in X .
\end{aligned}
$$

Thus we have shown (21). Now, letting $j \rightarrow \infty$ in (21), we get

$$
T=T_{m_{0}} .
$$

Thus we have also proved that $T_{m}=T_{m_{0}}$ for each $m \in M_{0}$, which (in view of (15)) yields

$$
d\left(f(x), T_{m_{0}}(x)\right) \leq \frac{(1+s(m)) h(x)}{1-s(m)-s(1+m)}, \quad x \in X, m \in M_{0}
$$

This implies (7) with $T:=T_{m_{0}}$; clearly, equality (22) means the uniqueness of $T$ as well.

Remark 3 Note that from the above proof we can derive a much stronger statement on the uniqueness of $T$ than the one formulated in Theorem 3. Namely, it is easy to see that $T:=T_{m_{0}}$ is the unique additive mapping such that (19) holds with some $L>0$.

\section{Competing interests}

The author declares that he has no competing interests.

Received: 30 July 2013 Accepted: 4 October 2013 Published: 08 Nov 2013

\section{References}

1. Brillouët-Belluot, N, Brzdęk, J, Ciepliński, K: On some recent developments in Ulam's type stability. Abstr. Appl. Anal. 2012, Article ID 716936 (2012)

2. Czerwik, S: Functional Equations and Inequalities in Several Variables. World Scientific, London (2002)

3. Fă̌ziev, VA, Rassias, TM, Sahoo, PK: The space of $(\psi, \gamma)$-additive mappings on semigroups. Trans. Am. Math. Soc. 354, 4455-4472 (2002)

4. Hyers, DH: On the stability of the linear functional equation. Proc. Natl. Acad. Sci. USA 27, $222-224$ (1941)

5. Hyers, DH, Isac, G, Rassias, TM: Stability of Functional Equations in Several Variables. Birkhäuser, Boston (1998)

6. Hyers, DH, Isac, G, Rassias, TM: On the asymptoticity aspect of Hyers-Ulam stability of mappings. Proc. Am. Math. Soc. $126,425-430$ (1998)

7. Hyers, DH, Rassias, TM: Approximate homomorphisms. Aequ. Math. 44, 125-153 (1992)

8. Jung, S-M: Hyers-Ulam-Rassias Stability of Functional Equations in Mathematical Analysis. Hadronic Press, Palm Harbor (2001)

9. Jung, S-M: Hyers-Ulam-Rassias Stability of Functional Equations in Nonlinear Analysis. Springer Optimization and Its Applications, vol. 48. Springer, New York (2011)

10. Moszner, Z: On the stability of functional equations. Aequ. Math. 77, 33-88 (2009)

11. Ulam, SM: A Collection of Mathematical Problems. Interscience, New York (1960). Reprinted as: Problems in Modern Mathematics. Wiley, New York (1964)

12. Hyers, DH: Transformations with bounded $m$ th differences. Pac. J. Math. 11, 591-602 (1961)

13. Hyers, DH, Ulam, SM: On approximate isometries. Bull. Am. Math. Soc. 51, 288-292 (1945)

14. Hyers, DH, Ulam, SM: Approximate isometries of the space of continuous functions. Ann. Math. 48, $285-289$ (1947)

15. Hyers, DH, Ulam, SM: Approximately convex functions. Proc. Am. Math. Soc. 3, 821-828 (1952)

16. Pólya, G, Szegö, G: Aufgaben und Lehrsätze aus der Analysis I. Springer, Berlin (1925)

17. Pólya, G, Szegö, G: Problems and Theorems in Analysis I. Springer, Berlin (1972)

18. Rassias, TM: On the stability of the linear mapping in Banach spaces. Proc. Am. Math. Soc. 72, 297-300 (1978) 
19. Rassias, TM: Problem. Aequ. Math. 39, 309 (1990)

20. Rassias, TM: On a modified Hyers-Ulam sequence. J. Math. Anal. Appl. 158, 106-113 (1991)

21. Aoki, T: On the stability of the linear transformation in Banach spaces. J. Math. Soc. Jpn. 2, 64-66 (1950)

22. Gajda, Z: On stability of additive mappings. Int. J. Math. Math. Sci. 14, 431-434 (1991)

23. Rassias, TM, Šemrl, P: On the behavior of mappings which do not satisfy Hyers-Ulam stability. Proc. Am. Math. Soc. $114,989-993(1992)$

24. Rassias, TM, Šemrl, P: On the Hyers-Ulam stability of linear mappings. J. Math. Anal. Appl. 173, 325-338 (1993)

25. Brzdęk, J: A note on stability of additive mappings. In: Rassias, TM, Tabor, J (eds.) Stability of Mappings of Hyers-Ulam Type, pp. 19-22. Hadronic Press, Palm Harbor (1994)

26. Brzdęk, J: Hyperstability of the Cauchy equation on restricted domains. Acta Math. Hung. 141, 58-67 (2013)

27. Brzdęk, J, Ciepliński, K: A fixed point approach to the stability of functional equations in non-Archimedean metric spaces. Nonlinear Anal. 74, 6861-6867 (2011)

28. Brzdęk, J, Chudziak, J, Páles, Z: A fixed point approach to stability of functional equations. Nonlinear Anal. 74, 6728-6732 (2011)

29. Cădariu, L, Găvruța, L, Găvruța, P: Fixed points and generalized Hyers-Ulam stability. Abstr. Appl. Anal. 2012, Article ID 712743 (2012)

30. Brzdęk, J: Stability of the equation of the p-Wright affine functions. Aequ. Math. 85, 497-503 (2013)

31. Brzdęk, J: A hyperstability result for Cauchy equation. Bull. Aust. Math. Soc. (2013). doi:10.1017/S0004972713000683

32. Bahyrycz, A, Piszczek, M: Hyperstability of the Jensen functional equation. Acta Math. Hung. (2013). doi:10.1007/s10474-013-0347-3

33. Piszczek, M: Remark on hyperstability of the general linear equation. Aequ. Math. (2013). doi:10.1007/s00010-013-0214-x

34. Piszczek, M, Szczawińska, J: Hyperstability of the Drygas Functional Equation. J. Funct. Spaces Appl. 2013, Article ID $912718(2013)$

35. Baker, JA: The stability of certain functional equations. Proc. Am. Math. Soc. 112, 729-732 (1991)

36. Cădariu, L, Moslehian, MS, Radu, V: An application of Banach's fixed point theorem to the stability of a general functional equation. An. Univ. Vest. Timiş., Ser. Mat.-Inform. 47, 21-26 (2009)

37. Cădariu, L, Radu, V: Fixed point methods for the generalized stability of functional equations in a single variable. Fixed Point Theory Appl. 2008, Article ID 749392 (2008)

38. Ciepliński, K: Applications of fixed point theorems to the Hyers-Ulam stability of functional equations - a survey. Ann. Funct. Anal. 3, 151-164 (2012)

10.1186/1687-1812-2013-285

Cite this article as: Brzdęk: Stability of additivity and fixed point methods. Fixed Point Theory and Applications 2013, 2013:285

\section{Submit your manuscript to a SpringerOpen ${ }^{\ominus}$ journal and benefit from:}

- Convenient online submission

- Rigorous peer review

Immediate publication on acceptance

Open access: articles freely available online

- High visibility within the field

- Retaining the copyright to your article 